\title{
Lucha agraria y equipamiento de deseo en el contexto de la reactivación de la industria azucarera uruguaya Un abordaje marxista-deseante
}

\author{
Alex Martins Moraes ${ }^{1}$ \\ ${ }^{1}$ CIS-IDES, CONICET, Buenos Aires, Argentina \\ (iD) https://orcid.org/o000-0002-9306-2133 \\ Correo electrónico: alexmartinsmoraes@gmail.com
}

Recibido:

febrero de 2020

Aceptado:

septiembre de 2021

doi: $10.34096 /$ cas.i53.7521

\section{Resumen}

En este artículo analizo cómo las demandas agrarias de un sindicato de trabajadores rurales del extremo norte del Uruguay han sido administradas en el marco de una política gubernamental de desarrollo que pretendió convertir a sus respectivos beneficiarios en productores eficientes de caña de azúcar. Desde una perspectiva que conjuga el pensamiento de Gilles Deleuze y Félix Guattari con el análisis marxiano de los sistemas de crédito, examino la convergencia conflictiva entre lucha agraria y desarrollo rural, conceptualizándola como un equipamiento inestable de captura del deseo colectivo. A través de la observación participante y en diálogo con los beneficiarios de las políticas de desarrollo en el norte uruguayo, evalúo las consecuencias económicas del "equipamiento de deseo", señalo sus condiciones de (im)posibilidad y los caminos para su posible superación política. Finalizo reflexionando sobre la primacía creadora del deseo respecto de todo proceso de captura que apunte a encauzarlo y funcionalizarlo.

\section{Agrarian struggle and desire equipment in the context of the reactivation of the Uruguayan sugar industry. A Marxist-desiring approach}

\begin{abstract}
This article analyzes how the agrarian demands of a rural workers' union in northern Uruguay were managed within the framework of a government development policy, which attempted to convert its beneficiaries into efficient sugarcane producers. From a perspective that combines the thinking of Gilles Deleuze and Félix Guattari with Marxian analysis of credit systems, I examine the conflicting convergence between agrarian struggle and rural development, conceptualizing it as unstable 'collective equipment' [équipement collectif] that captures social desire. Through participant observation and through interacting with the beneficiaries of development policies, I examine the
\end{abstract}

\section{Palabras clave}

Lucha agraria; Política de desarrollo; Deseo; Marxismo; Uruguay
Key words

Agrarian struggle; Development policy; Desire; Marxism; Uruguay 
economic consequences of desire equipment and point to its conditions of (im)possibility, as well as to the ways of overcoming it politically. I conclude by reflecting on the primacy of desire over any capture process that aims to organize and functionalize it.
Palavras-chave

Luta agrária; Política de desenvolvimento; Desejo; Marxismo; Uruguai

\section{A luta agrária e o equipamento do desejo no contexto da reati- vação da indústria açucareira uruguaia. Uma abordagem marxista- desejante}

\section{Resumo}

Neste artigo, analiso como as reivindicações agrárias de um sindicato de trabalhadores rurais do extremo norte do Uruguai foram administradas no marco de uma política estatal de desenvolvimento que pretendeu transformar seus respectivos beneficiários em produtores eficientes de cana-de-açúcar. Partindo de uma perspectiva que conjuga o pensamento de Gilles Deleuze e Félix Guattari com a análise marxiano dos sistemas de crédito, examino a convergência conflituosa entre a luta agrária e o desenvolvimento rural, conceitualizando-a como um equipamento instável de captura do desejo coletivo. Através da observação participante, e em diálogo com os beneficiários das políticas de desenvolvimento implementadas no extremo norte uruguaio, avalio as consequências econômicas do equipamento de desejo, sinalizo suas condições de (im)possibilidade, assim como os caminhos para sua possível superação política. Finalizo refletindo sobre a principalidade do desejo no que diz respeito a qualquer processo de captura que pretenda canalizá-lo e funcionalizá-lo.

Raúl Sendic Antonaccio, poema inédito.

Si el control de los caminos te pregunta adónde vas

le dirás que a tu destino.

$Y$ al decirte -ipero cuál?, no sé, pero lo persigo sé que queda más allá.

\section{Introducción}

Durante la última década, en distintos países de Sudamérica, hemos sido invitados por nuestros gobernantes a adherir a las grandes promesas asociadas al desarrollo económico y la redistribución de la riqueza. La adhesión a estas promesas, y el usufructo de sus materializaciones más palpables, sedimentaron amplios consensos sociales en torno a los proyectos políticos de los llamados gobiernos progresistas suramericanos. Pese a sus particularidades, cabe señalar que los distintos progresismos apostaron a la movilización de las personas en pos del desarrollo, lo que implicó incluirlas como parte de las nuevas estrategias de acumulación capitalista y establecer una síntesis entre sus deseos de una vida mejor y las soluciones políticas formuladas desde las esferas gubernamentales. Dado que el desarrollismo progresista ha combinado actividades extractivas de materias primas con políticas sociales destinadas a la inclusión social y productiva de la gente, podemos decir que sus condiciones de posibilidad se han jugado en dos frentes estratégicos, a saber: 1) el investimento capitalista del territorio, y 2) la funcionalización de los deseos colectivos en el marco de unas estrategias de 
acumulación solidarias con diferentes tipos de capital. ${ }^{1}$ En el presente artículo, me ocuparé de un conjunto de procedimientos administrativos que son inherentes a este segundo frente estratégico.

A partir de un estudio de caso en la ciudad de Bella Unión, ubicada en el extremo norte del Uruguay, abordaré las políticas de desarrollo rural impulsadas por sucesivos gobiernos del Frente Amplio como un procedimiento de movilización de la capacidad deseante de las personas y, específicamente, como un intento de convertir dicha capacidad en un esfuerzo productivo disciplinado y eficaz. A lo largo de esta exposición, veremos que la articulación entre los objetivos estratégicos del gobierno uruguayo - representados por la empresa estatal Alcoholes del Uruguay Sociedad Anónima (ALUR) - y las aspiraciones y necesidades cultivadas en el seno del sindicato de la Unión de Trabajadores Azucareros de Artigas (UTAA) ha resultado sumamente inestable. Si bien ambos actores lograron involucrarse en un esfuerzo productivo común, sus cursos de acción divergieron paulatinamente, lo que puso en cuestión el contenido mismo de la política de desarrollo que los movilizaba. Tuve la oportunidad de acompañar el despliegue de tales divergencias durante diversas incursiones a Bella Unión, emprendidas entre 2013 y 2015 en el marco de una investigación más amplia que indagaba en las articulaciones y disyunciones entre políticas populares y políticas estatales de desarrollo económico. El trabajo de campo en el norte uruguayo me permitió seguir de cerca la expansión del complejo agroindustrial local, entrevistar a sus múltiples protagonistas — planificadores, cuadros políticos del Frente Amplio, sindicalistas, pequeños productores- y conocer sus respectivas rutinas laborales, inquietudes y apuestas colectivas. Dicho proceso de interlocución me autoriza a reconstruir, en el presente trabajo, el diagrama administrativo diseñado por los planificadores uruguayos para absorber las reivindicaciones agrarias presentadas por el movimiento popular de Bella Unión. La recuperación esquemática de la estructura institucional destinada a producir un alineamiento entre organización popular y estrategia estatal desarrollista será suplementada con el rastreo de las tensiones internas a dicha articulación, las cuales me propongo abordar como devenires disfuncionales del deseo colectivo.

Cuando se enmarca en una perspectiva orientada al seguimiento de los procesos deseantes, el análisis de las dinámicas de sujeción y subjetivación ya no puede partir de la distribución aparente de los emplazamientos sociales, sino que debe instalarse allí donde la gente se atribuye a sí misma algo que desear o, alternativamente, es confrontada con la necesidad de mediar su deseo en objetos y conceptos que se le interponen desde afuera. Diremos, ante todo, que el deseo humano es del orden del pensamiento; en palabras de Deleuze (2005, p. 183), es "posición de deseo en el pensamiento": implica la instalación de categorías intelectivas mediante las cuales los sujetos volverán decible y comunicable el eventual vislumbre de su nuevo "poder-ser". Así, pues, un abordaje deseante empieza donde el deseo se torna enunciable. No importan primordialmente las posiciones sociales en las que el individuo se encuentra inscripto (trabajadores, productores rurales, etc.), sino su posición de deseo, o sea, el montaje deseante singular que lo sitúa en tensión o en convergencia con el lugar que le tocó ocupar en un mundo determinado. La cuestión, entonces, no es cómo un individuo transita de una posición social a otra, sino cómo se desplaza de un montaje colectivo de deseo a otro y qué impacto tiene ese movimiento respecto de las posiciones sociales a las que se lo pretendía fijar. ¿Las reitera? ¿Las hace colapsar? ¿Las excede hacia otros campos de posibles?

En lo concerniente a las dinámicas de montaje y captura del deseo colectivo, mi abordaje se beneficiará de los aportes teóricos Gilles Deleuze (1995) y Félix Guattari (2013). A su vez, el análisis marxiano ${ }^{2}$ de los sistemas de crédito y las formulaciones de Frédéric Lordon (2015) acerca de las condiciones de (im)posibilidad del "patronato" capitalista me permitirán evidenciar en qué puntos se volvió impracticable la sutura entre
1. Zibechi (2010) analiza cómo el neoextractivismo se conjuga con la inclusión de las "organizaciones sociales" en la gestión de las políticas sociales de los gobiernos progresistas. Gago y Mezzadra (2015) desmenuzan la articulación entre programas no contributivos de transferencias monetarias y reproducción ampliada de las finanzas.

2. En el campo de estudios suscitado por la obra de Marx y la de sus seguidores, el término "marxiano" alude a la producción teórica del pensador alemán, mientras que el término "marxista" se refiere a la amplia tradición político-teórica que se constituyó en torno al pensamiento de Marx. En este artículo, mi caracterización del sistema de crédito recurre únicamente a fuentes marxianas. 
3. Silvina Merenson (2016) relata las derivas de UTAA entre la lucha sindical y la apuesta revolucionaria. Asimismo, en lo que se refiere a la emergencia de la lucha agraria y sindical en el norte uruguayo, cabe mencionar el trabajo de Yamandú González (1994) y el comprometido relato de Mauricio Rosencof (1989).

el deseo de desarrollo estimulado por el gobierno uruguayo y un deseo de bienestar material cultivado por aquellos miembros de UTAA que se dejaron enrolar en el aparato desarrollista. En el primer apartado, recupero el proceso de movilización que enfrentó a los trabajadores de la caña de azúcar del norte uruguayo con la estrategia agroindustrial de la empresa ALUR. En el segundo apartado, discuto las nociones deleuzo-guattarianas de "agenciamiento" y "equipamiento de deseo". Argumento que la primera contribuye al análisis de determinados esfuerzos colectivos orientados a la activación de la capacidad inventiva de las personas, mientras que la segunda permite evaluar cómo dicha capacidad es investida por un aparato productivo jerárquico y solidario con la acumulación del capital. Al partir de tales coordenadas teóricas, pasaré a analizar, en el tercer apartado, las condiciones de posibilidad para la inclusión de los trabajadores rurales de Bella Unión en la estructura del complejo agroindustrial nucleado por ALUR. También dilucidaré en qué circunstancias el deseo de bienestar que animaba a las bases de UTAA hacia mediados de los años 2000 no pudo prolongarse en el deseo de acumulación de capital fomentado por los planificadores uruguayos a cargo del Complejo Sucro-Alcoholero de Bella Unión. Evaluaré las consecuencias económicas y subjetivas de tal situación y relataré un proceso de organización colectiva que se propuso trascenderla. En mis palabras finales, luego de sintetizar los resultados del análisis, esbozaré una hipótesis de trabajo y algunas conceptualizaciones provisionales de cara a investigaciones futuras.

\section{Lucha agraria y desarrollo en Bella Unión}

Desde mediados del siglo XX, la economía de Bella Unión depende de la producción azucarera. El movimiento popular de esa ciudad es muy activo y está dinamizado, fundamentalmente, por la militancia de UTAA. Los orígenes del sindicato se remontan al año 1961, cuando Raúl Sendic Antonaccio, un joven estudiante de Derecho vinculado al Partido Socialista, respaldó con sus conocimientos jurídicos y orientaciones ideológicas la radicalización del incipiente sindicalismo rural del extremo norte uruguayo. Liderados por Sendic, los cortadores de caña impulsaron una intensa secuencia de lucha popular, la cual rebasó los límites de la reivindicación sindical e incorporó un fuerte énfasis en la reforma agraria y en la prédica revolucionaria. Entre 1964 y 1971, UTAA marchó cinco veces a Montevideo bajo consignas tales como "Tierra para el que la trabaja" y "Por la tierra y con Sendic". En ese mismo período, Sendic dejó el Partido Socialista, organizó la lucha armada del Movimiento de Liberación NacionalTupamaros (MLN-T) y pasó a la clandestinidad. Algunos militantes de UTAA lo acompañaron en su gesta guerrillera, de modo que el sindicato quedó directamente asociado al campo político del MLN-T y se convirtió, así, en el blanco de una feroz represión estatal en los primeros años de la dictadura cívico-militar instalada en $1973 .{ }^{3}$

La redemocratización del Uruguay, a mediados de los años 1980, favoreció la reorganización del sindicato y la formación de una nueva generación de dirigentes populares, quienes se propusieron actualizar a su manera las apuestas políticas de antaño. En un contexto marcado por el ajuste neoliberal, la apertura de los mercados regionales y la consecuente bancarrota de la economía azucarera bellaunionense, la UTAA se acercó a la plataforma electoral del Frente Amplio, el partido que congrega a las principales fuerzas de la izquierda y la centro-izquierda uruguayas desde 1971. En el año 2005, el Frente Amplio finalmente ganó las elecciones presidenciales y empezó a poner en marcha una política de reactivación de la agroindustria bellaunionense. Sin embargo, la tensión entre los funcionarios del nuevo gobierno progresista y los sindicalistas de UTAA se hizo sentir rápidamente. En enero de 2006, justamente cuando el gobierno nacional había empezado a invertir raudales de dinero en la ampliación de la industria azucarera de Bella Unión, los cortadores de caña decidieron ocupar tierras fiscales y 
dar inicio a la plantación de alimentos por su cuenta y riesgo. El escándalo mediático y político fue estruendoso.

Al esgrimir la histórica consigna "Tierra para el que la trabaja", los ocupantes de tierras manifestaban su voluntad de convertirse en pequeños productores rurales y participar en la administración de los esfuerzos desarrollistas emprendidos por el gobierno nacional. Menos comprometidos con la política económica frenteamplista que con las apuestas colectivas formuladas en el marco de su sindicato, los trabajadores de la caña de azúcar identificaron en la estrategia gubernamental de desarrollo económico una buena oportunidad para canalizar nuevas y viejas exigencias de justicia y bienestar social. Ante este escenario, desde el año 2007, el gobierno aceptó repartir tierras entre algunos cortadores de caña en aras de convertirlos en productores rurales eficientes, habilitados a proveer materia prima al ingenio azucarero local, bajo control de la empresa estatal ALUR. Sin embargo, las autoridades uruguayas jamás favorecieron la inclusión de los trabajadores rurales en la administración directa de su política de desarrollo: así empezaba a ponerse en marcha el denominado Complejo Sucro Alcoholero de Bella Unión (en adelante, CSA), una intervención desarrollista verticalizada que el gobierno del Frente Amplio encaró como la piedra fundamental de un nuevo "Uruguay Productivo". La inclusión de los ocupantes de tierras de 2006 en el diagrama productivo del CSA fue el disparador de un proceso de movilización capitalista del deseo colectivo cuyos mecanismos de efectivización constituyen mi foco de interés en la tercera parte de este trabajo. Antes de examinarlos, será necesario discutir las herramientas conceptuales que informan mi análisis.

\section{El desarrollo como equipamiento colectivo de deseo}

A mediados de los años 2000 se produjo un tenso debate en torno a las posibles alternativas a lo que John Friedman (2006) denominó "el impasse posestructuralista" en la antropología del desarrollo. Los trabajos de James Ferguson (1994) y Arturo Escobar (1995), que hasta entonces habían sido referentes obligatorios, empezaban a ser cuestionados desde las llamadas "perspectivas orientadas a los actores" (Arce y Long, 2000; Bierschenck, 2008). Estas últimas, a su vez, apostaban a un pasaje de la textualidad y el análisis de discurso hacia el estudio detallado de las situaciones concretas de interacción, al asumir que el desarrollo está siempre expuesto al poder transformador de las demandas locales. En este contexto de intensa discusión académica, fue Pieter De Vries $(2007,2015)$ quien hizo uno de los usos más estimulantes de las contribuciones de Gilles Deleuze, Alain Badiou y Jacques Lacan a la hora de analizar las dimensiones utópicas y deseantes inherentes a la promesa desarrollista. Sin declinar de la pretensión crítica, de Vries asumió parcialmente la conceptualización fergusoniana de la "máquina antipolítica" (Ferguson, 1994, p. 254) para, luego, matizarla desde una perspectiva según la cual las políticas de desarrollo inauguran un ciclo pretendidamente inexorable - y fundamentalmente inconsistente- de estímulo y aniquilación del deseo colectivo. La perspectiva teórica que introduzco a continuación se asemeja a la de De Vries, pero parte de premisas algo distintas a las de este autor - aun cuando comparta con él algunos referentes teóricos fundamentales- $-{ }^{4}$ Para contemplar el caso de Bella Unión, me vi ante la necesidad de construir un enfoque teórico en el cual las políticas de desarrollo no constituyen el punto de partida privilegiado para el análisis de la producción deseante y la imaginación política, sino que deben pensarse como una respuesta a estas últimas, es decir, como un intento de administrarlas mediante unos diagramas políticos e institucionales que les son ampliamente ajenos y que responden, en primera instancia, a los paradigmas de gobierno adoptados por el poder público o la iniciativa privada en cada contexto nacional. De ahí que las nociones de "equipamiento" y "agenciamiento" de deseo resulten centrales en el presente trabajo.
4. Discuto la originalidad del aporte que hace de Vries en el campo de los estudios del desarrollo en Moraes (2015). Asimismo, en Moraes (2019) sugiero situar su programa teórico-investigativo el marco de lo que denomino "nuevas sensibilidades comunistas" en el terreno de la investigación social contemporánea. 
Jeremy Gould (2007) fue quizá el primer autor en defender la productividad del concepto de "agenciamiento" para abordar las prácticas sociales derivadas del "desarrollo". En la propuesta de Gould, dicho concepto indica que las "prácticas sociales" vinculadas al desarrollo estarían constituidas por dos elementos inseparables: el primero es epistémico - "desarrollo es un conjunto de ideas que se aglutinan a través de actos discursivos y no-discursivos ('enunciaciones') que evocan la noción de desarrollo" (Gould, 2007, p. 281) - y el segundo es "social", básicamente porque la composición del agenciamiento implica la movilización de actores sociales concretos. En tanto "agenciamiento socio-epistémico", el desarrollo consistiría en una "configuración de ideas, prácticas y actores" que está balizada por dos ejes, uno "vertical" y otro "horizontal" (Gould, 2007, p. 283). En el eje horizontal, habría elementos heterogéneos - personas, diagramas organizacionales, máquinas, etc.- que se juntan para producir resultados específicos. En el eje vertical - es decir, ordenador- se multiplicarían ciertas representaciones de la realidad que, una vez apropiadas como hechos pertinentes, se convertirían en objetos de intervención administrativa. Los vectores de ordenamiento que operan en el eje vertical entrarían en "constante tensión" con "prácticas y artefactos a través de los cuales la heterogeneidad se reafirma: resistencia, contradicción, tensión, conflicto" (Gould, 2007, p. 283).

La definición que utiliza Gould del concepto deleuzo-guattariano de "agenciamiento" se encuentra en la obra Mil Mesetas, donde leemos lo siguiente:

Según un primer eje, horizontal, un agenciamiento comporta dos segmentos: uno de contenido y otro de expresión. Por un lado, él es agenciamiento maquínico de cuerpos, de acciones y pasiones, mezcla de cuerpos reaccionando unos sobre los otros; por otro lado, [es un] agenciamiento colectivo de enunciación, de actos y de enunciados, transformaciones incorpóreas siendo atribuidas a los cuerpos. Pero, según el eje vertical orientado, el agenciamiento tiene, por una parte, lados territoriales o reterritorializados que lo estabilizan, y por otra parte, picos de desterritorialización que lo arrebatan. (Deleuze y Guattari, 1995, p. 29)

Esta definición básica de agenciamiento aparece en el segundo tomo de la obra en cuestión. Sin embargo, en los tres tomos siguientes, el concepto se pone a prueba en diversos tipos de configuraciones sociales y recibe decenas de adjetivaciones y especificaciones. Después de todo, en la perspectiva deleuzo-guattariana, no hay nada que no se sostenga por medio de agenciamientos. Tiene poca importancia, por lo tanto, constatar que el "desarrollo" es un agenciamiento donde existen orden y resistencia, fijaciones paralizantes por un lado y relaciones creadoras por otro. El desafío del análisis es evaluar con qué tipo de agenciamiento estamos enfrentados. Guattari (2013) propone una distinción entre la "función de equipamiento colectivo" y la "función de agenciamiento colectivo". Ambas, grosso modo, constituyen agenciamientos. Lo que cambia son las "máquinas abstractas" incluidas en cada una de ellas. Por máquinas abstractas debemos entender los procesos de ideación y creatividad que se proponen explorar nuevas posibilidades de expresión en las variables físicas y semióticas disponibles en cada lugar y momento: "una máquina abstracta $[\ldots]$ tiene $[\ldots]$ un papel piloto [...] No funciona para representar, aunque sea algo de real, sino que construye una realidad por venir, un nuevo tipo de realidad" (Deleuze y Guattari, 1995, p. 29).

En referencia a lo que relaté en el primer apartado, podemos decir que la ocupación de tierras del año 2006 hizo proliferar un conjunto de máquinas abstractas que se daban a conocer bajo la forma de consignas políticas. Estas consignas afirmaban, básicamente, que los trabajadores no solo podrían convertirse en productores rurales, sino que también estaban en condiciones de cogobernar el CSA. La ocupación de tierras protagonizada por UTAA logró actualizar ciertas capacidades subjetivas que otorgaban materialidad a las consignas en cuestión. En una perspectiva deleuzo-guattariana, las 
subjetividades necesarias para la estructuración del socius están montadas sobre unidades básicas de producción interpoladas, es decir, componentes materiales y semióticos - también llamados máquinas deseantes- que se determinan mutuamente y sedimentan distintos modos de existencia. En estos términos, la tierra, los ocupantes de tierras y determinadas consignas políticas fueron algunas de las máquinas deseantes amalgamadas en el agenciamiento colectivo "ocupación de tierras del 2006". Este agenciamiento supo explorar en sus componentes maquínicos una serie de potencialidades que no estaban actualizadas en ellos de antemano. Así, por ejemplo, hubo asalariados rurales que se volvieron ocupantes de tierras, en sintonía con ciertas consignas enraizadas en la memoria de antiguas luchas sociales; también hubo tierras que se transformaron en una "ocupación" y fueron trabajadas de acuerdo con las posibilidades que se pretendía explorar en ellas y en sus respectivos ocupantes. En síntesis, diversas máquinas deseantes se acoplaron unas a otras para realizar el campo de posibles prefigurado por las consignas de la militancia sindical. Esto fue así hasta que dichas máquinas se vieron investidas por un curso de acción más poderoso, desencadenado por la empresa ALUR. A partir de entonces, la tierra ocupada en forma extralegal por los trabajadores en 2006 acabó asimilada - junto con sus ocupantes-al nuevo complejo sucroalcoholero en vías de implementación. La producción de caña, iniciada por los propios trabajadores por su cuenta y riesgo en las parcelas ocupadas, se volvió objeto de estímulo y financiación para la industria azucarera reactivada. Simultáneamente, más tierras fueron puestas a disposición de los trabajadores, solo que esta vez estaban equipadas con mecanismos de acceso muy precisos, definidos en la oficina del director general de ALUR: habría cobranza de arrendamiento; sus "beneficiarios" deberían tramitar personería jurídica para recibirlas; la caña de azúcar sería el cultivo prioritario, y su introducción, mantenimiento y cosecha dependerían de una financiación sujeta a cobranza de intereses.

Guattari (2013) observa que cuando pasamos de los agenciamientos colectivos a los equipamientos, también transitamos de un régimen de máquinas abstractas a otro: "con los equipamientos, el conjunto de las máquinas abstractas depende de un mando único - el Capital - en torno del cual se organiza todo un estado mayor que cuadricula [...] el conjunto de las coordenadas y los valores del campo social" (p. 93). Por esta razón, de acuerdo con el autor, los equipamientos podrían considerarse "condiciones de posibilidad de toda infraestructura económica capitalística" (p. 30). Así como sucede en cualquier agenciamiento colectivo, la materia prima de la "función de equipamiento" es el deseo de las personas, concretamente abordado a partir de mecanismos de captura y organización solidarios con una programación general relativamente cerrada, que obtiene en el proceso de circulación del capital sus criterios de ordenamiento. Tenemos, entonces, que la tierra siguió siendo máquina deseante en el complejo productivo diagramado por ALUR, pero junto a ella se perfilaron nuevas máquinas -crédito, monocultivo con mercado asegurado, etc. - que hicieron que el deseo colectivo fuera mediado en otro régimen de producción; un régimen compatible, por lo menos abstractamente, con la estabilidad de un complejo agroindustrial orientado al abastecimiento del mercado interno de azúcar y bioetanol.

La noción de "patronato", tal y como la desarrolla Frédéric Lordon (2015), nos ayuda a recorrer la filigrana de la mediación del deseo colectivo en los equipamientos capitalistas. El patronato consiste, básicamente, en la captura y la subordinación de la capacidad de actuar de las personas, en beneficio del despliegue de un "deseo-amo" dotado de sus propios objetos de realización (Lordon, 2015, p. 25). En el patronato capitalista, el deseo-amo ambiciona, primordialmente, la producción de valor y la acumulación de capital y, para hacerlo, debe operar como una "potencia que enrola potencias" y asegura el involucramiento satisfactorio de los individuos con aquellas actividades que condicionan la obtención de sus fines últimos (p. 53). Este proceso de "alineamiento" del deseo no requiere que patrones y subordinados posean exactamente las mismas expectativas o se "esfuercen" siempre en la misma dirección. Es 
5. El "capital portador de interés" es una suma de dinero que el capitalista financiero adelanta a otro capitalista - llamado "operante" - para que este la invierta en alguna actividad productiva, genere plusvalor y la devuelva a su punto de partida con un determinado porcentaje de incremento. Las consecuencias de la operatoria de este tipo de capital en el contexto del CSA serán analizadas en detalle a continuación.

6. Moraes (2012) y Chiape y Espasandín (2014) analizan en detalle las particularidades organizativas de las distintas unidades productivas que componen el CSA. suficiente con que su articulación operatoria sea lo más funcional posible desde el punto de vista del "deseo-amo" (p. 55). Esto equivale a decir que debe haber por lo menos algunos puntos de convergencia entre ambos flujos de deseo. Tal convergencia implica, lógicamente, la fijación de un conjunto de objetos de realización - “máquinas deseantes", dirían Deleuze y Guattari- cuya adquisición implique cierto compromiso con los propósitos del patronato. Sin embargo, la dinámica de alineamiento -o equipamiento- del deseo subordinado puede desajustarse cuando este último se proyecta sobre un campo de expectativas que relativizan - o abstraen - el curso de acción diseñado para satisfacerlo en simbiosis con el deseo-amo. Esta disfunción del deseo subordinado evidencia la imposibilidad de suturar la capacidad de movilización de las personas sobre un campo estable de objetos de realización y revela, así, la posibilidad de que el sujeto deseante postule un horizonte singular de devenir cuya manifestación debilita el poder de captura del deseo-amo. Cuando se trata — como en el caso de Bella Unión- de un proceso de conversión de trabajadores zafrales en productores agrícolas eficientes y capitalizados, y cuando dicho proceso se asienta en un sistema de crédito, la desviación del deseo subordinado tendería a ocurrir justamente en el momento en que no se cumplan los requisitos necesarios a la adecuada inversión productiva del capital prestado. En este caso, lo que Marx (1983) denomina "capital portador de interés" 5 se convierte en un tipo de recurso completamente ajeno a los fines que lo habían tornado disponible y, por tanto, en un vector de desestabilización de todo el equipamiento colectivo que él debería afianzar. En el siguiente apartado me dedicaré, precisamente, al mapeo de esos devenires (dis)funcionales del deseo desde su captura sobre el "deseo-amo" hasta su proyección sobre unas formas de satisfacción ampliamente incompatibles con el equipamiento que alguna vez se propuso encauzarlos y estimularlos.

\section{3. ¿Del deseo de salario al deseo de capital?}

Como vimos en el primer apartado, en el año 2006, un conjunto de trabajadores rurales vinculado a UTAA interpeló al gobierno uruguayo con un llamado a la inversión en la agricultura familiar y, además, se propuso participar directamente en la planificación del proyecto de desarrollo agroindustrial programado para Bella Unión. Ante estos planteos, la repuesta de la administración de ALUR consistió en arrendar 400 hectáreas a un terrateniente de la zona, fraccionarlas en 39 lotes y adjudicarlas a los militantes sindicales mediante un contrato de subarrendamiento. Para volverse productores cañeros en esas tierras, los "beneficiarios" deberían formar empresas unipersonales con la finalidad de contratar empleados, recibir los financiamientos ofrecidos por ALUR y venderle materia prima. Conocida como Campo Placeres y diseñada unilateralmente por ALUR, esta primera experiencia de acceso a la tierra integrada por militantes de organizaciones sociales de Bella Unión entró en funcionamiento en el año 2007. Seis años después, ya se habían instalado otras dos unidades productivas con características similares a las del modelo original, que totalizaban unas 1400 hectáreas bajo control de exasalariados rurales. ${ }^{6}$

Desde el año 2007 en adelante, la estrategia gubernamental de reparto de la tierra entre los trabajadores rurales bellaunionenses consistió en retener el momento reivindicativo de la lucha agraria emprendida por UTAA (i.e., “Tierra para el que la trabaja”) y apartar su dimensión políticamente experimental, que consistía en asegurar a los asalariados rurales una participación deliberativa en las políticas de desarrollo del gobierno. Esta situación no impidió que UTAA siguiera defendiendo una ampliación paulatina de la distribución de lotes agrícolas entre sus afiliados, pero ahora la lucha de la organización se restringía al horizonte de posibilidades establecido por ALUR. En otras palabras, UTAA empezó a reclamar tierras para que sus militantes se convirtieran en productores 
de caña de azúcar. Sin embargo, esta demanda se inscribía en un campo de expectativas bastante particular, cultivado sistemáticamente en los espacios de articulación política impulsados por el sindicato. Rocha, quien se desempeñó como presidente de UTAA entre 2007 y 2015, buscaba resumir tales expectativas con las siguientes palabras:

La idea que tenemos de todo eso [el acceso a la tierra] no es que los compañeros se crean productores. Es sacarlos de la zafralidad para que puedan mantener a sus familias, comer todo el año, tener una entrada de dinero para mandar a estudiar a los hijos, vivir decentemente y no tener que rendir cuenta a ningún patrón. (Rocha, presidente de UTAA, Bella Unión, entrevista realizada en septiembre de 2013)

Bajo el liderazgo de Rocha, el sindicato pretendió difundir entre sus militantes la promesa del desarrollo como una promesa de estabilidad laboral, ampliación de la capacidad de consumo de las familias obreras y suspensión de la dependencia patronal. En esta prédica, quedaba opacado el hecho de que volverse un productor cañero también significaba convertirse en patrón, reclutar mano de obra -muchas veces la de sus antiguos compañeros de lucha sindical-y explotarla en forma eficiente, así como las demás fuerzas productivas puestas bajo su responsabilidad. Rocha aceptó el riesgo de conjugar el reclamo por tierras con la aceptación del monocultivo cañero, aunque ello implicara reproducir las mismas relaciones laborales que el sindicato había cuestionado históricamente. Para atenuar la contradicción, este dirigente ponía en un segundo plano el compromiso capitalista inherente al proyecto productivo de ALUR, mientras enfatizaba en su discurso la eventual mejora de las condiciones de vida de los aspirantes a tierras.

Antes de incorporarse a las rutinas productivas del complejo agroindustrial en la condición de pequeños productores cañeros financiados por ALUR, los militantes de UTAA beneficiados por la política de desarrollo del gobierno nacional eran asalariados zafrales. Así, la inestabilidad laboral representaba una preocupación central para ellos, y la posible superación de ese drama, en los términos formulados por Rocha, les sonaba interesante. Ahora bien, hay que señalar que no existe una relación a priori entre, por un lado, la voluntad de obtener un trabajo estable y, por el otro, la decisión de tornarse un productor eficiente de caña de azúcar. La oportunidad de producir caña, por sí sola, valdría muy poco si no estuviera mediada por la garantía inmediata de un salario fijo y por la promesa de una mejora relativa de las condiciones de vida. Ante esta complexión deseante, estimulada en el ámbito del sindicato, ¿qué elemento podría volver realmente atractiva, para los trabajadores zafrales, la propuesta de acceso a la tierra planteada por ALUR? El elemento en cuestión eran, precisamente, los créditos productivos que la empresa se dispuso a asignar mensualmente a sus proveedores de materia prima.

Dado que los trabajadores rurales zafrales devenidos en productores de caña no poseerían medios de subsistencia a lo largo del año mientras no contaran con los dividendos provenientes de la venta de materia prima al ingenio, y dado que era la disponibilidad de estos medios de subsistencia la que hacía del ingreso a la tierra una promesa seductora para la militancia sindical, la empresa ALUR formuló una estrategia de financiamiento que consistía en lo siguiente: primero se discriminaban los gastos anuales de mantenimiento de una hectárea de caña de azúcar, después este valor se multiplicaba por la extensión de los cañaverales abarcados por cada unidad productiva y se dividía por el número de sus integrantes. Por lo general, la suma resultante representaba lo equivalente a uno o dos salarios mínimos por mes. Al final de la zafra, el dinero adelantado por ALUR era descontado del precio pagado por la materia prima comprada por el ingenio, con una tasa de interés del 7,5\% al año. Bajo estas condiciones, parecía introducirse la posibilidad de un alineamiento entre el deseo de salario estable activado en el sindicato y el deseo de acumulación promulgado por ALUR. No obstante, las condiciones de 
posibilidad para el enrolamiento de algunos miembros de UTAA en el proyecto de ALUR fueron, también, las condiciones de imposibilidad para su compromiso eficiente con el proceso productivo. Veamos por qué.

$\mathrm{Si}$, en el contexto del sindicato, los futuros productores de caña definieron algunos criterios básicos para la realización de su enrolamiento en el CSA, entonces ALUR, a su vez, se encargó de definir los mecanismos de ejecución de dichos criterios. Así, en respuesta a la expectativa obrera de obtener una fuente de ingreso estable, la empresa generó una figura "salarial" sui generis de naturaleza crediticia. En cuanto a la dependencia patronal, de la cual los trabajadores pretendían distanciarse, su atenuación fue parcialmente concretada en la medida en que los nuevos productores cañeros estaban autorizados a definir su propia rutina laboral. Finalmente, el incremento de la capacidad de consumo quedaría asegurado por la posibilidad formal de acceso, por parte de las familias de agricultores, a los excedentes de capital resultantes de la producción cañera. Sin embargo, esto último dependería de que el monto de dinero obtenido con la venta de materia prima al ingenio fuera superior al crédito contraído con ALUR y a los gastos de reinversión requeridos por cada unidad productiva. Puede decirse, entonces, que quienes en un principio adhirieron al CSA en busca de un flujo constante de dinero se encontraron, en la práctica, con una remesa mensual de crédito ("salarios") y con una remesa anual de excedentes, denominada "libre disponibilidad" (o sea, lucro). Con todo, tanto el crédito como la "libre disponibilidad" desempeñaban apenas un papel estratégico potencial en lo concerniente a la valorización del capital. Revisemos, muy brevemente, sus dinámicas esenciales.

El crédito, desde el punto de vista del deudor, es dinero que él no tiene y que está a su disposición a cambio del pago de intereses. Desde el punto de vista del acreedor, es garantía de apropiación de un valor futuro. Si quien recibe el crédito está al frente del proceso de producción, como era el caso de los nuevos productores agrícolas del CSA, entonces su función consiste en usarlo para producir plusvalor $\mathrm{y}$, al cabo de cierto período, retornarlo a su punto de partida - es decir, ALUR - como interés. Respecto del ciclo del capital portador de intereses, Marx (1983) argumenta que se trata de un movimiento de conservación del valor que conecta al "capitalista monetario" (ALUR) con el "capitalista funcionante" (productores cañeros) de cara a la producción de plusvalor. El poseedor del capital no lo da como medio de pago ni lo vende, sino que lo presta "bajo la condición de que, primero, [el dinero] vuelva, luego de determinado plazo, a su punto de partida y, segundo, de que vuelva como capital realizado, habiendo realizado su valor de uso de producir plusvalor" (Marx, 1983, p. 259). Marx hace un comentario aclarador sobre cómo el crédito dinamiza, simultáneamente, la producción material y el forzamiento de una subjetivación capitalista: "aun cuando un hombre sin fortuna obtiene crédito como industrial o comerciante, eso se da por la confianza de que él actuará como capitalista, se apropiará del trabajo no pagado con el capital prestado. El crédito le es dado como capitalista en potencial" [El énfasis es mío] (Marx, 1983, p. 112). A su vez, el lucro garantiza la continuidad de la producción, no solo porque puede reinvertirse, sino también porque es la suposición de su existencia futura la que justifica la activación de un sistema de crédito. El lucro empresarial impone a su poseedor - en caso de que él esté interesado en seguir ampliándolo en el futuro- la necesidad de invertirlo como capitalista. La ganancia empresarial extraída del plusvalor generado en el proceso de producción debe invertirse en fuerzas productivas y medios de producción si el capitalista pretende reducir paulatinamente la participación del prestamista en el rateo del lucro bruto final.

Sin embargo, un corto circuito empezaba a instalarse en el seno del CSA cuando, ya en la etapa de su conversión en "capitalistas potenciales", los productores tendían a afrontar la ganancia empresarial recibida al final de una zafra como medio de intercambio, es decir, como dinero común y corriente que no tiene utilidad estratégica desde el punto 
de vista de la valorización del capital. Es que el dinero transferido por ALUR a los agricultores en forma de lucro neto ("libre disponibilidad") no solo era deseado desde un principio como medio de intercambio - y, por razones que veremos a continuación, se parecía insidiosamente a él一, sino que también era instrumentalizado como tal por los exasalariados de UTAA, lo que redundaba en su resalarización en las mallas del CSA.

Como ya había anticipado, la frecuencia de la distribución de remesas de crédito y lucro por parte de ALUR a lo largo del año las volvía muy semejantes a la transferencia de dinero entre el empleador y el empleado en una relación salarial convencional, en la cual el capital del primero es movilizado como medio de intercambio por el segundo en el mercado de bienes de consumo. Conforme mencioné anteriormente, los "beneficiarios" del CSA recibían créditos mensuales equiparables a uno o dos salarios mínimos y, al término de la zafra, se tornaban depositarios de un monto de dinero denominado "libre disponibilidad". Este último era interpretado como una especie de aguinaldo. ${ }^{7}$ A su vez, los créditos mensuales otorgados por ALUR - llamados "adelantos", "mensualidades" o "sueldos" por sus receptores- se asemejaban formalmente a un salario, puesto que su recibo acarreaba el desempeño de tareas específicas, bajo la supervisión técnica de los funcionarios del ingenio.

El lucro neto obtenido gracias a la venta de materia prima, cuya producción resultaba de la explotación de la fuerza de trabajo propia y ajena, sería la condición para que los nuevos colonos tuvieran la oportunidad de aumentar - reinversión mediantesus excedentes futuros. No obstante, en el año 2015, los exasalariados de UTAA que producían caña en las principales unidades productivas del CSA llevaban algunos años sin recibir la "libre disponibilidad". Diversos factores confluían para determinar la inexistencia de excedentes en las unidades productivas controladas por exasalariados rurales - pago de intereses, baja productividad de la caña debido a imprevistos climáticos, altos costos de irrigación, flete y arrendamiento, etc.-, pero todos estos factores, sean cuales sean, solo tenían impacto decisivo sobre la inviabilidad de la acumulación porque los colonos jamás adhirieron a un régimen de ahorro de fondos y de reinversión capaz de mitigarlos o contrarrestarlos. Tales circunstancias limitaban fuertemente la autonomía de cada unidad productiva, lo cual las convertía en lugares de trabajo completamente orientados a atender las necesidades de la industria azucarera.

Una vez reseñados los efectos económicos inherentes al difícil intento de convertir el deseo de salario en deseo de capital, corresponde, ahora, examinar sus efectos subjetivos.

\subsection{Efectos subjetivos del equipamiento de deseo}

En el año 2015, Pachu, exmilitante de UTAA y productor de caña en el CSA, me explicaba que

el único dinero-dinero, que vos podés decir, 'este dinero es el trabajo del mes', en el caso mío y de mi hermano, son 27.000 pesos por mes. De ahí tenemos que pagar los créditos que tengamos [se refiere a créditos de consumo en el banco y en el comercio] y vivir. (Pachu, Bella Unión, julio de 2015)

El "dinero-dinero" de Pachu era básicamente un medio de intercambio que le daba acceso a una cantidad estable de servicios y mercancías todos los meses, pero que no lo ponía en condiciones de transformar las circunstancias que fijaban y estabilizaban su modo de vida actual. Apropiado como "salario", el crédito otorgado por ALUR garantizaba el compromiso laboral de los nuevos productores con la estrategia económica del CSA. Sin embargo, al generar deuda, este dinero conducía a la paulatina eliminación de la "libre disponibilidad" o, por lo menos, a su drástica reducción. Dado
7. Esa yuxtaposición de registro se tornaba evidente al final de cada año, cuando, al no recibir la "libre disponibilidad" debido a problemas asociados a la baja productividad de la caña, o en razón de los voluminosos descuentos realizados por ALUR para saldar los créditos pendientes, los productores se movilizaban como si fueran asalariados de la compañía con la finalidad de reivindicar dinero para "pasar las fiestas". 
que los agricultores también solían emplear la "libre disponibilidad" como medio de intercambio - es decir, como "dinero-dinero" destinado al consumo improductivo-, su potencialidad capitalista terminaba neutralizada. En consecuencia, las unidades productivas administradas por exasalariados rurales experimentaban serias dificultades para diversificar la producción y terminaban ampliamente subordinadas a ALUR, o sea, monopolizadas por la industria en lo relativo a sus objetivos actuales y futuros.

El monopolio del futuro constituye, para Maurizio Lazzarato (2017), un efecto de poder crucial del crédito. La deuda, inherente a las operaciones financieras de capital, es un dispositivo de cierre y anticipación del tiempo, justamente porque hipoteca su indeterminación y, de esta forma, lo normaliza, sustrayéndole toda la acción creadora (Lazzarato, 2017, p. 82). Este efecto de poder era fundamental en una intervención desarrollista como la existente en Bella Unión, ya que en ella la movilización del deseo ajeno era tan importante cuanto su alineamiento con el "deseo-amo": un deseo que no puede existir aislado, persiguiendo sus objetos con medios propios, sino solamente "involucrado en relaciones a las que quiere dar la forma de la subordinación" (Lordon, 2015, p. 64). En convergencia con la crítica marxiana de la economía política, hay que reconocer en el capital un elemento que no solo disuelve ciertos lazos sociales, sino que también constituye una condición de afianzamiento de nuevas relaciones de dependencia y cooperación. Es en este sentido que el movimiento del capital distribuye funciones económicas, las vincula entre sí y las enraíza en formas apropiadas de subjetivación. También es importante distinguir el capital, en sus distintas formas, del "dinero-dinero" (medio de intercambio). Mientras este último es susceptible de múltiples usos y valoraciones de orden moral (Wilkis, 2015), el capital, para existir, exige la fijación de posiciones de sujeto que, de no sedimentarse, interrumpen el proceso de acumulación y lo diluyen.

Así, pues, si alguien recibe capital y lo usa como "dinero-dinero" - o deja de ejecutar las funciones productivas que asegurarían su restitución al prestamista con intereses- el proceso de acumulación queda comprometido en los dos polos del sistema de crédito: el donante de capital pierde la oportunidad de valorizarlo, mientras que el receptor hace colapsar su uso productivo potencial. Esto último fue lo que sucedió con los exasalariados rurales que administraban unidades productivas subordinadas a ALUR. En ellas, el consumo improductivo de dinero, y el relajamiento del trabajo productivo, se superpusieron a la disciplina capitalista preconizada por la industria, lo que evidenció un choque paralizante entre dos regímenes contradictorios de deseo que, no obstante, confluyeron en el CSA y debieron coexistir tensamente en su ámbito.

Al recordar luchas pasadas, Pachu evaluaba, con lágrimas en los ojos, que los "tremendos esfuerzos [emprendidos por UTAA]" en el afán de "meter a la gente en la tierra" culminaron en un éxito paradojal, que a veces parecía un fracaso: "todos los proyectos que ha hecho UTAA han quedado en... han fracasado. Entre comillas fracaso. [...] Somos privilegiados los que estamos en las colonias, porque nosotros estuvimos del otro lado y se vive mejor estando en las colonias. Es indiscutible" (Pachu, Bella Unión, julio de 2015). En ocasiones, producir caña para ALUR y vivir mejor también significaba entristecerse, porque en las unidades productivas subordinadas al CSA la satisfacción económica individual emergía indisociable de la renuncia parcial o total, provisional o definitiva, a los viejos proyectos colectivos. Si, en la ocupación de tierras del 2006, se establecieron consignas que anticipaban nuevas vocaciones productivas para el suelo y nuevas posiciones de poder para la militancia popular, entonces después de la instalación del CSA esas proyecciones tendieron a dirimirse en los mecanismos "apropiados". Así, quien quisiera tierra, plantaría caña y pagaría arrendamiento; quien quisiera salario, recibiría créditos; y quien quisiera consumir más debería aprender a acumular capital. Por supuesto que los imperativos en cuestión se alejaron sustancialmente de sus objetivos estratégicos formales, en razón de los devenires disfuncionales de un deseo 
de salario que no pudo transmutarse en deseo de capital. Pero si bien estos devenires frustraban el deseo-amo, no por ello dejaban de estar bajo su imperio, puesto que sus consecuencias transgresivas generaban endeudamiento y este, a su vez, precarizaba el despliegue de nuevas formas de realización personal y colectiva.

\subsection{Sustracción deseante}

En el año 2015, ante el impasse de las experiencias de colonización realizadas en el marco del CSA, un grupo de nuevos dirigentes de UTAA reemplazó a Rocha en la dirección del sindicato y decidió problematizar abiertamente lo que percibía como una seria contradicción entre, por un lado, las políticas de acceso a la tierra aseguradas por ALUR y, por el otro, la histórica lucha de la organización en contra de las formas de explotación del trabajo inherentes a la producción cañera y a favor de una política agraria contundente, basada en la diversificación productiva y el cultivo de alimentos. Este punto de inflexión política condujo a la apertura de un nuevo proceso de movilización colectiva que ya no apuntaba a conjugar los deseos y las consignas de la militancia sindical con los mecanismos de captura y funcionalización desplegados por ALUR.

A lo largo del año 2015, la nueva Comisión Directiva de UTAA organizó sucesivas reuniones en la sede del sindicato para planificar un "proyecto piloto" de acceso a la tierra orientado a la agricultura familiar y al abastecimiento de los mercados locales. La tarea de elaboración del "proyecto piloto" estuvo totalmente a cargo de los trabajadores interesados en implementarlo, quienes recurrieron a sus propios conocimientos productivos - construidos en el marco de múltiples experiencias laborales en el sector agrícola- para definir qué uso debería hacerse de la tierra una vez que lograran conquistarla. El resultado de ese intenso trabajo de planificación fue el diseño de una "unidad productiva diversificada" que debería servir como referencia para una "política global de reforma agraria" (UTAA, 2015). La militancia de UTAA entendió que dicho proyecto podría resultar pertinente para promover el acceso a la tierra no solo en el norte del país, sino también en todas aquellas regiones del Uruguay en donde hubiera trabajadores rurales asalariados dispuestos a dejar atrás la dependencia patronal y dedicarse a la producción de alimentos. A la hora de formular su política agraria, los militantes del sindicato evitaron hacer concesiones a los protocolos de colonización ya existentes en el contexto del CSA. Había una inviabilidad institucional a priori en el proyecto elaborado por UTAA, puesto que en él, el acceso a la tierra no suponía ningún tipo de contrapartida material (se descartaba la posibilidad de pagar arrendamientos), mientras que los estímulos a la producción - llamados "becas de trabajo" - se presentaban como estipendios no reembolsables, cuya finalidad era garantizar el sustento de las familias de productores rurales durante la etapa de consolidación de sus cooperativas. No por casualidad, en las pancartas que elaboró la dirección de UTAA para anunciar el nuevo ciclo de reivindicaciones agrarias inaugurado por el sindicato, se leía la siguiente consigna: "Por una reforma agraria real y generosa".

A su vez, los trabajadores encargados de la formulación del "proyecto piloto" de reforma agraria decidieron difundir sus reclamos en primera persona, a través de un video que pretendían publicar en YouTube. Entusiasmado con esta iniciativa, les ofrecí mi cámara filmadora y los ayudé a improvisar un sistema de iluminación en el local de UTAA. La puesta en escena tuvo lugar una tarde de noviembre de 2015: al fondo colgaba una histórica bandera enarbolada por el sindicato en las marchas de la década de 1960. Posicionados frente a la cámara, mis interlocutores comunicaron sus decisiones y expectativas en estos términos: "no queremos endeudarnos - decían-, queremos producir alimentos sanos; queremos que la tierra sea un bien común al servicio de las aspiraciones del pueblo". Desde el 2015 en adelante, el deseo colectivo otrora subordinado a ALUR empezó a fluir hacia nuevos dominios y pudo reengendrar sus propios objetivos. De este modo, dejó de existir únicamente como una distorsión del curso de 
acción trazado por el deseo-amo de la agroindustria azucarera. En síntesis, el reclamo obrero de tierras, trabajo y bienestar se sustrajo al territorio, las condiciones y los objetos de satisfacción determinados por ALUR. Tuvo inicio, entonces, un nuevo proceso de agenciamiento. Tal proceso logró relativizar los mecanismos de captura instaurados por ALUR e hizo que la tierra - convertida en el sustrato de las capacidades creadoras de la política- informara el despliegue sin ambages de unos deseos de bienestar que se hicieron irreductibles al "deseo-amo" agroindustrial.

\section{Palabras finales}

En este artículo examiné cómo las experiencias de acceso a la tierra organizadas en el marco del Complejo Sucro Alcoholero de Bella Unión han sido capaces de sedimentarse mediante un "equipamiento colectivo de deseo". Dicho equipamiento consistió en la selección y el estímulo financiero de unas voliciones y capacidades colectivas cuyo desarrollo debería contemplar el reordenamiento de las funciones productivas de las personas, lo que exigía redefinir su relación con los medios de producción y sus formas de recibir el dinero y lidiar con él. La herramienta clave del equipamiento colectivo impulsado por la empresa ALUR consistió en un sistema de crédito que pretendía asegurar la conversión de algunos trabajadores rurales provenientes de las bases de UTAA en sujetos aptos para la acumulación de capital. Vimos que el sistema de crédito en cuestión contempló parcialmente las demandas de bienestar nutridas en el contexto del sindicato, a la vez que determinó ampliamente las actividades productivas a las cuales su militancia debería adherir. Así, tuvo lugar una política agraria indisociable del endeudamiento y el monocultivo cañero.

Procuré evidenciar que los procesos de equipamiento de deseo son inestables y no siempre tienen un éxito cabal: sus efectos variables responden, necesariamente, a la variabilidad de las expectativas que pretenden movilizar en beneficio de su reproducción. Esto quedó claro cuando los trabajadores de UTAA fueron incluidos en el CSA a partir de la movilización de su deseo de salario fijo e incremento del ingreso familiar. $\mathrm{Al}$ encarar los flujos de crédito y lucro asignados por ALUR como un fondo de consumo potencial ("dinero-dinero"), los trabajadores experimentaron inmediatamente los beneficios materiales en nombre de los cuales se dejaron reclutar. Sin embargo, al hacerlo, ellos también comprometieron el desarrollo de las fuerzas productivas esperado por el gobierno uruguayo y se volvieron completamente dependientes de los créditos de ALUR para preservar el modo de vida alcanzado gracias al acceso a la tierra. En el transcurso de ese proceso, resultó evidente para algunos de mis interlocutores que las capacidades colectivas reivindicadas por ellos en la secuencia política previa al equipamiento colectivo - me refiero a la ocupación de tierras del año 2006- estaban definitivamente postergadas.

La retención, en el nivel de la conciencia, de los horizontes políticos que habían informado las luchas sindicales de antaño, y la constatación de que su contenido solo podría subsistir en forma muy parcial en los territorios del complejo agroindustrial, constituyeron el disparador de un nuevo agenciamiento colectivo, es decir, de una sustracción del deseo subordinado a los objetos que tendían a fijarlo y hacerlo funcional en el marco del equipamiento desarrollista. Hacia el año 2015, un grupo de nuevos dirigentes de UTAA decidió extrañarse de aquellos compromisos productivos que deberían emparejar la lucha agraria con los objetivos estratégicos de ALUR. Como alternativa a la captura del deseo de tierras y bienestar en el marco del CSA, el sindicato de los cortadores de caña se esforzó por agenciar las aspiraciones de sus bases sociales en referencia a una posible "reforma agraria real". Esta situación, que denominé una "sustracción deseante", me permite ahora sugerir, a modo de hipótesis para futuros trabajos, que el deseo no es solo aquello cuya movilización - ya sea bajo la forma de agenciamiento 
o de equipamiento- sedimenta y actualiza ciertos modos de existencia y composición colectiva. El deseo es actividad: constituye una potencia básica de suspensión y reconfiguración del lazo social.

El deseo sería, entonces, lo que insiste sobre objetos que supuestamente ya no forman parte del poder-ser del sujeto deseante - o que son insignificantes desde el punto de vista del régimen de captura y ordenamiento que rige su vida en un momento y lugar dados-. En estos términos, el movimiento del deseo coincidiría con el del viajero poetizado por Raúl Sendic en el epígrafe de este artículo. Se trata de un movimiento que va "más allá", sin saber exactamente adónde. Experimenta. Al fin y al cabo, la fijación sobre un conjunto predefinido de objetos de satisfacción no es la culminación del proceso deseante, sino tan solo un punto de sutura que lo bascula sobre determinado dominio funcional y lo detiene en pleno camino, pero sin agotarlo. En su movimiento exploratorio fundamental, el deseo es lo que excede y agota todo equipamiento. Y lo hace porque, aun habiendo sido capturado, preserva su capacidad de proyectarse sobre una multiplicidad de nuevos objetos -incluso aquellos que, a simple vista, parecerían haber sido reemplazados o definitivamente suprimidos.

\section{Financiamiento}

Este documento es resultado del financiamiento otorgado por el Estado Nacional, por lo tanto queda sujeto al cumplimiento de la Ley № 26.899. Organismo financiador: CONICET. Programa de Becas Doctorales Tipo II, Latinoamericanas. Argentina.

\section{Agradecimientos}

Agradezco al CONICET por la beca doctoral que me permitió desarrollar la investigación que subsidia este trabajo. Gracias a Silvina Merenson y a mis compañerxs del Colectivo Máquina Crísica por los diálogos decisivos que mantuvimos en los últimos años.

\section{Biografía}

Doctor en Antropología Social y Cultural por el Instituto de Altos Estudios Sociales, Argentina. Realiza investigaciones en el campo de la antropología del desarrollo, indagando especialmente en la dialéctica y la disyunción entre políticas de Estado y políticas populares. 


\section{Q Referencias bibliográficas}

》 Arce, A. y Long, N. (2000). Anthropology, development and modernities. Londres: Routledge.

»Bierschenck, T. (2008). Anthropology and Development. Institut für Ethnologie und Afrikastudien Working Papers, 87, 1-21.

"Chiappe, M. y Espasandín, N. (Eds.). (2014). El acceso a la tierra en cuestión: dependencia y autonomía en la Colonia Raúl Sendic Antonaccio. Montevideo: Letraeñe.

»De Vries, P. (2007). Don't compromise your desire for development! A Lacanian/Deleuzian rethinking of the anti-politcs machine. Third World Quarterly, 29(1), 25-43.

»De Vries, P. (2015). The Real of Community, the Desire for Development and the Performance of Egalitarianism in the Peruvian Andes. Journal of Agrarian Change, 15(1), 65-88.

»Deleuze, G. (2005). Derrames. Buenos Aires: Cactus.

»Deleuze, G. y Guattari, F. (1995). Mil Platôs. Capitalismo e esquizofrenia. Vol. 2. Río de Janeiro: Editora 34.

"Escobar, A. (1995). La invención del tercer mundo. Bogotá: Norma.

" Ferguson, J. (1994). The Anti-Politics Machine. Cambridge: Cambridge University Press.

» Friedman, J. (2006). Beyond the post-structural impasse in the Anthropology of Development. Dialectical Anthropology, 201(30), 201-225.

"Gago, V. y Mezzadra, S. (2015). Para una crítica de las operaciones extractivas del capital. Patrón de acumulación y luchas sociales en el tiempo de la financiarización. Nueva Sociedad, 255, 38-52.

"González, Y. (1994). Los olvidados de la tierra. Vida, organización y luchas de los sindicatos rurales. Montevideo: Nordam.

» Gould, J. (2007). (Dis)assembling development. En J. Gould, y L. Siitonen (Eds.), Anomalies of Aid (pp. 269-295). Helsinki: Interkont.

» Guattari, F. (2013). Líneas de fuga. Buenos Aires: Cactus.

"Lazzarato, M. (2017). O Governo do Homem Endividado. San Pablo: n-1.

"Lordon, F. (2015). Capitalismo deseo y servidumbre. Marx y Spinoza. Buenos Aires: Tinta Limón.

» Marx, K. (1983). O Capital. Libro II. São Paulo: Abril Cultural.

»Merenson, S. (2016). Los peludos: cultura, política y nación en los márgenes del Uruguay. Buenos Aires: Gorla.

»Moraes, Á. (2012). ¿Campo en disputa? El acceso a la tierra de los trabajadores de UTAA al "Campo Placeres" en Bella Unión (tesis de grado). Universidad de la República, Facultad de Agronomía, Montevideo, Uruguay.

" Moraes, A. (2015). Antropología del desarrollo: entre la máquina anti-política y la máquina deseante. Trama, 6, 23-32.

» Moraes, A. (2019). iSigan ese "movimiento real”! Sensibilidades comunistas e investigación social contemporánea. Insurgentes, 1(2), 135-169.

»Rosencof, M. (1989). La rebelión de los cañeros y los hombres del arroz. Montevideo:TAE. 
"Wilkis, A. (2015). Sociología moral del dinero y el mundo popular. Estudios Sociológicos, 33(99), 553-578.

"Zibechi, R. (2010). Políticas sociales, gobiernos progresistas y movimientos antisistémicos. Otra economía, 4(6), 32-42.

\section{Otras fuentes consultadas}

》UTAA. (2015). Bases para la creación de una unidad productiva diversificada. Recuperado de https://utaasindicato.files.wordpress.com/2015/11/bases-unidad-productiva-reforma-agraria1.pdf 
